\title{
ASSISTÊNCIA JUDICIÁRIA NO DIREITO CABO-VERDIANO
}

\author{
JUDICIAL ASSISTANCE IN CAPE VERDEAN LAW
}

José Lopes da Graça

Diretor do Gabinete de Estudos, Planeamento Estratégico e Cooperação Institucional do Ministério da Justiça e Trabalho de Cabo Verde

Doutorando em Ciências Sociais pela Universidade do Mindelo (S. Vicente - Cabo Verde) em Cooperação com a Universidade de Valladolid, Espanha

jlopesg_an@hotmail.com

\section{RESUMO}

O instituto da assistência judiciária ensaia a sua projeção no ordenamento jurídico caboverdiano por meio de instrumentos internacionais anteriores à própria Constituição. É propósito destas reflexóes analisar de perto esse instituto e compreender melhor o tratamento que lhe é dispensado tanto pelo legislador constitucional nacional como pelo legislador comum ordinário. $\mathrm{O}$ trabalho apresenta-se dividido em seis partes, a saber: uma primeira, reservada à delimitação conceitual do instituto de assistência judiciária, distinguindo-o de outros conceitos e figuras afins; a segunda parte propóe fazer o cotejo entre a assistência judiciária e os direitos humanos buscando demonstrar que a assistência judiciária traduz-se numa vertente dos direitos humanos; a terceira parte é dedicada à assistência judiciária na Constituição cabo-verdiana; a quarta se reporta ao tratamento infraconstitucional da assistência judiciária; a quinta parte versa sobre as instituiçóes intervenientes na promoção da assistência judiciária e, por fim, a sexta apresenta como pano de fundo uma reflexão sobre a implementação formal e material do instituto da assistência judiciária no sistema jurídico nacional.

Palavras-chave: Acesso à justiça. Assistência judiciária. Carenciado. Direito fundamental. Gratuito. 


\section{ABSTRACT}

The judicial assistance institute rehearses its projection in the Cape Verde legal system through international instruments prior to the Constitution itself. It is the purpose of these reflections to examine this institute closely and to better understand the treatment accorded to it by both the national constitutional legislator and the ordinary ordinary legislator. The paper is divided into six parts: a first, reserved for the conceptual delimitation of the institute of legal aid, distinguishing it from other concepts and similar figures; the second part proposes to make a comparison between legal aid and human rights, seeking to demonstrate that judicial assistance is a human rights dimension; the third part is dedicated to legal aid in the Cape Verdean Constitution; the fourth relates to the infraconstitutional treatment of legal aid; the fifth part deals with the institutions involved in the promotion of legal aid and finally the sixth presents a reflection on the formal and material implementation of the legal aid institute in the national legal system.

Keywords: Access to justice. Judicial assistance. Needy. Fundamental right. Free.

Data de submissão: 26/03/2018

Data de aceitação: 11/07/2018

\section{SUMÁRIO}

INTRODUÇÃO 1. CONCEITO DE ASSISTÊNCIA JUDICIÁRIA 2. ASSISTÊNCIA JUDICIÁRIA E DIREITOS HUMANOS 3. ASSISTÊNCIA JUDICIÁRIA NA CONSTITUIÇÃO DA REPÚBLICA DE CABO VERDE 4. TRATAMENTO INFRACONSTITUCIONAL DA ASSISTÊNCIA JUDICIÁRIA 5. INSTITUIÇŌES INTERVENIENTES NA PROMOÇÃO DA ASSISTÊNCIA JUDICIÁRIA 6. IMPLEMENTAÇÃO FORMAL E MATERIAL DO INSTITUTO DA ASSISTÊNCIA JUDICIÁRIA. CONSIDERAÇÓES FINAIS. 


\title{
INTRODUÇÁO
}

O direito de acesso à justiça é um imperativo constitucional. Resulta do disposto no artigo $22^{\circ}$ da Constituição de Cabo Verde (CRCV). Não se compadece com a carência de meios ou de recursos económico-financeiros e nem cede perante a indisponibilidade momentânea desses recursos, quer por razóes meramente estruturais ou mesmo conjunturais, por parte de quem necessite ter acesso em tempo útil aos serviços de justiça, a fim de, por essa via, poder fazer valer em juízo, um direito ou interesse juridicamente protegido.

\begin{abstract}
A incapacidade económica que justifica a concessão de apoio judiciário deve, concretamente, ser aferida tendo em conta os custos concretos de cada ação e a disponibilidade da parte que a solicita, não estando excluído que seja concedido, em maior ou menor medida, a cidadãos com capacidade económica bem superior à média, se o valor da causa assim o justificar. ${ }^{1}$
\end{abstract}

Denegar àqueles que careçam de meios para suportar os custos com a demanda, a faculdade de acesso aos tribunais e por essa via poder legitimamente, pleitear em juízo, corresponderia à violação de pelo menos dois princípios fundamentais: o princípio da igualdade e o princípio da não discriminação (artigo $24^{\circ} \mathrm{da} \mathrm{CRCV}$ ), além, obviamente, de comprometer o direito de acesso à justiça que, como já se viu, reporta-se a um direito fundamental do cidadão. A disposiçấo do artigo $22^{\circ}$ da CRCV estaria inserida no elenco daqueles dispositivos constitucionais a que determinados autores denominam de "normas constitucionais de eficácia limitada". Tais tipos de normas se preocupam com a reposição do princípio da igualdade, impondo:

Restriçóes e deveres aos poderes governantes e, em contrapartida, conferem direitos subjetivos aos governados. Situam-se predominantemente entre os dispositivos que estatuem sobre as declaraçóes dos direitos fundamentais e democráticos e, garantias constitucionais desses direitos. ${ }^{2}$

A assistência judiciária é uma manifestação do direito de acesso à justiça e surge pela primeira vez tratada no ordenamento jurídico de Cabo Verde pós-independente, através da Lei no ${ }^{\circ}$ 35/III/88, de 18 de julho. A primeira Constituição cabo-verdiana de 1980,

$\overline{1}$ V.g. a esse propósito, Jorge Miranda e Ri Medeiros, in "Constituição da República Portuguesa, Anotada. Tomo I, Introduçáo Geral, Preâmbulo, artigos 1º a 79º, 2005.

2 Consultar José Afonso da Silva, in "Aplicabilidade das normas constitucionais", Revista dos Tribunais, 1968, pp. 774. 
publicada no suplemento ao Boletim Oficial no. 41, de 13 de outubro, de 1980, não contemplava nenhuma disposição a esse respeito, embora pelo seu catálogo "dos direitos, liberdades, garantias e deveres fundamentais dos cidadãos" (artigos 25 a 48 ) se possa aferir que o legislador constitucional já tivesse de algum modo tido contacto com os meandros da Declaração Universal dos Direitos Humanos de 1948 e, por conseguinte, tomado ciência dos normativos que enformam esse importante instrumento do Direito Internacional Público, particularmente do seu artigo $8^{\circ}$ que alude precisamente à essa temática. Tal matéria, como se pode constatar, já não passou despercebida ao legislador constitucional da segunda república (1992).

\section{CONCEITO DE ASSISTÊNCIA JUDICIÁRIA}

A assistência judiciária não pode ser confundida com acesso à justiça, informação jurídica e nem com apoio judiciário, entre outros conceitos similares. Por seu lado no contexto constitucional a assistência judiciária surge associada a outras dimensões, designadamente, às de direito ao patrocínio judiciário, direito à informação jurídica e direito à tutela jurisdicional. A garantia da via judiciária (...), embora esteja inserida no capítulo relativo aos direitos fundamentais e, se refira expressamente apenas a direitos, não se restringe naturalmente à defesa dos direitos fundamentais, pelo que acesso à justiça é um conceito mais amplo. ${ }^{3}$ Vem contemplado no artigo $22^{\circ}$ da Constituição, com o mesmo título o qual dedica todos os seus seis números a essa matéria. De maior abrangência que a noção de assistência judiciária, o acesso à justiça pressupóe a criação de condiçóes objetivas para que os cidadãos, de um modo geral, com ou sem condiçóes financeiras, possam de facto usufruir desse bem. ${ }^{4}$

A par da manutenção da ordem, segurança e prossecução do bem comum, a criação das condiçóes de "acesso à justiça” inscreve-se de igual modo entre os fins e objetivos do Estado, cabendo a esta entidade operacionalizar esse acesso para que o mesmo seja

\footnotetext{
3 Referindo-se à disposição constitucional portuguesa (artigo 20. ${ }^{\circ}$ ) similar à sua congénere caboverdiana (artigo 22..$^{\circ}$ ), advogam Gomes Canotilho e Vital Moreira, que "este preceito reconhece dois direitos, conexos, mas distintos: (a) direito de acesso ao direito (n. $\left.{ }^{\circ} 1\right)$ e (b) o direito de acesso aos tribunais (n. ${ }^{\circ}$ 2). A sua conexão é evidente, pois o conhecimento dos seus direitos (e dos seus deveres) por parte de cada um é condiçáo para os exercer e fazer valer (e para cumprir e observar os deveres). In "Constituição da República Portuguesa Anotada", 1984.

4 A esse respeito, v.g. Ana Prata in Dicionário Jurídico, Direito Civil, Direito Processual Civil, Organização Judiciária, com a colaboração de Jorge Carvalho, 2006, pp. 147 e ss.
} 
de facto uma realidade. ${ }^{5}$ Traduz-se ao fim e ao cabo no exercício de uma das funções do Estado, a função judiciária. ${ }^{6} \mathrm{~A}$ informação jurídica, sendo igualmente um direito com assento constitucional ( $\mathrm{n}^{\circ} .3$ do artigo $22^{\circ}$ da Constituição) visa apetrechar o cidadáo com conhecimentos jurídicos, o mínimo necessário que lhe permita tomar consciência das situaçôes subjetivas que lhe são favoráveis e, de igual modo, saber como utilizar os instrumentos jurídicos e institucionais disponíveis que lhe permitam a sua efetivação. Apoio judiciário traduz-se numa realidade mais restrita e circunscreve-se a uma situação já mais concreta. A Ordem dos Advogados de Cabo (OACV) presta apoio judiciário e os tribunais também. A primeira, disponibilizando profissionais do foro que possam acompanhar tecnicamente os seus constituintes em juízo e, os segundos, nomeando advogados que num caso concreto possam auxiliar o cidadáo que esteja pleiteando algum direito ou interesse juridicamente protegido, em tribunal.

Por conseguinte, apoio judiciário, difere dos dois outros conceitos pré-citados. Grosso modo podemos sustentar que a assistência judiciária traduz-se por via de regra num tipo de apoio a ser prestado em juízo, por imperativo constitucional e legal, a um determinado cidadão, por parte de um técnico de Direito (advogado ou solicitador judicial) de forma gratuita, por carência de recursos económico-financeiros daquele, para arcar com os custos do processo a fim de poder pleitear nos tribunais e, por essa via, fazer valer um direito seu mediante reconhecimento judicial do mesmo ou sua efetivação. Segundo Miranda:
A Constituição, pressupondo um sistema não gratuito, limita-se a estabelecer que a justiça não pode ser denegada por insuficiência de meios económicos, impondo tão-somente que sejam asseguradas às pessoas economicamente carenciadas formas de apoio que viabilizem a tutela dos seus direitos e interesses. ${ }^{7}$

O instituto apoio judiciário, no qual se insere a assistência judiciária tem como propósito "evitar que a alguém seja impedido ou dificultado o exercício dos respetivos direitos e o acesso aos tribunais, em razão da sua condição social ou cultural, ou por insuficiência de meios económicos”. Por outro lado, a assistência judiciária é informada:

\footnotetext{
5 Pedro Almiro Neves, invoca o ponto de vista de alguns que defendem que “(...) a política é um esforço para fazer reinar a ordem e a justiça pois o poder assegura o interesse geral e o bem comum contra a pressão das reivindicaçóes particulares". Mais adiante esclarece que "o Estado (...) é um meio de assegurar uma certa ordem social, uma certa integraçáo de todos na coletividade, para o bem comum.” In Textos de Introdução à Política, 1983.

6 Subscrevendo a posição de Giorgio del Vecchio, vidé Vitor Henriques e Belmiro Gil Cabrito in "Introdução à Política", Tomo I, 1990, pp.16-18.

7 MIRANDA, J.; MEDEIROS R. Constituiçáo Portuguesa Anotada. Tomo I, Introdução Geral, Preâmbulo, Artigos $1^{\circ}$ a $79^{\circ}, 2005$, pp. 180.
} 
Pela ideia de garantia do acesso aos tribunais pelos cidadáos que não dispuserem dos recursos económicos necessários para custear as despesas do pleito e os encargos do patrocínio judiciário. O instituto da assistência judiciária traduz-se na dispensa total ou parcial, do prévio pagamento das custas e/ ou no patrocínio judiciário gratuito, ou quase, por advogado nomeado por juiz. ${ }^{8}$

Este instituto que foi regido por várias leis, procura "concretizar os direitos consagrados no artigo $20^{\circ}$ da Constituição da República Portuguesa”. Trata-se de uma forma de garantir o acesso à justiça aos desvalidos da sorte, isto é, daqueles que momentaneamente não se encontram em condiçóes de poder assumir os seus próprios encargos com a demanda da justiça. A insuficiência económico-financeira poderá ser estrutural ou meramente conjuntural, ou seja, o assistido terá que ser efetivamente pobre ou então a sua insuficiência económico-financeira deve resultar de uma situação ou fator momentâneo e passageiro. O conceito de pobre prende-se com o nível de rendimentos que uma pessoa aufere ou entáo com o montante monetário a que tem acesso diariamente. Todos aqueles que auferem menos $100 \$ 00$ (o equivalente a pouco mais de um dólar) por dia são considerados estruturalmente pobres. Estes à partida poderão usufruir do benefício da assistência judiciária. Mas terão que provar isso em juízo mediante a exibição de uma certidão de pobreza a ser emitida pela Câmara Municipal da sua localidade. Por vezes pode suceder que o assistido que beneficiou-se da assistência judiciária venha, depois de resolvida a demanda, a estar em condições de poder arcar com os encargos do processo em virtude de uma eventual indemnização a receber com o fim do processo. Nesses casos, parece líquido que o beneficiário da assistência judiciária deva arcar com os encargos do processo seja com advogado, seja com as custas judiciais, entre outros.

\section{ASSISTÊNCIA JUDICIÁRIA E DIREITOS HUMANOS}

A “assistência judiciária” além de poder ser considerada um dos direitos humanos, traduz-se de igual modo num dos inúmeros direitos fundamentais consagrados na CRCV. Os direitos, liberdades e garantias individuais que constam dos catálogos das Constituiçôes são denominados de direitos fundamentais. E os direitos fundamentais têm sido catalogados em várias categorias, havendo quem entenda dever distingui-los em direitos de primeira, segunda, terceira e quarta geração, dependendo dos períodos e das 
circunstâncias que estiveram na base do surgimento de cada geração desses direitos. ${ }^{9}$ Serão considerados direitos da primeira geração “os ligados ao valor liberdade” e traduzemse nos "direitos civis e políticos. Sáo direitos individuais com caracter negativo por exigirem diretamente uma abstenção do Estado, seu principal destinatário”. São direitos fundamentais de segunda geração os chamados "direitos económicos, sociais e culturais", de "titularidade coletiva, com carater positivo, pois exigem atuaçóes do Estado". São de terceira geração aqueles direitos "ligados ao valor fraternidade ou solidariedade". Estão relacionados com “o desenvolvimento ou o progresso, ao meio ambiente e à autodeterminaçáo dos povos bem como, ao direito de propriedade sobre o património comum da humanidade e ao direito da comunicaçáo”. Por fim inserem nos direitos da quarta geração, os que "compreendem os direitos à democracia, à informaçáo e ao pluralismo". Por aí se pode ver que o direito à "assistência judiciária” estará melhor inserido nos direitos fundamentais da primeira geração, já que esse direito expressa de algum modo a solidariedade para com aqueles mais carenciados da sociedade num domínio concreto que é o de "acesso à justiça” gratuita. Por outro lado, existem vários níveis de direitos humanos dependendo do bem jurídico protegido. Assim sendo temos: o direito à vida, o direito à integridade física e moral, o direito ao património e à propriedade, o direito à honra e à consideração, o direito à intimidade, o direito à liberdade de circulação, direito à liberdade de expressão e de informação, entre muitos outros. Todos esses direitos são potencialmente violáveis mercê da liberdade ou do livre arbítrio de que o ser humano é dotado, inclusive, podendo utilizá-lo para violar os direitos dos demais homens, seus semelhantes, embora, não o devendo fazer. O direito de "acesso à justiça” e à "assistência judiciária”, podem também ser classificados como vertentes dos direitos humanos sendo tratados de forma clara, expressa e inequívoca, nos principais instrumentos do Direito Internacional Público, já ratificados pelo Estado de Cabo Verde. ${ }^{10}$ Assim, de entre uma trintena de artigos que constitui o elenco normativo da Declaração Universal dos Direitos do Homem, aprovada pela Assembleia Geral da Organização das Naçóes Unidas (ONU) a 10 de dezembro de 1948, um deles, o artigo $8^{\circ}$ estatui que "toda a pessoa tem direito a recurso para as jurisdiçôes nacionais competentes contra os atos que violem os direitos fundamentais reconhecidos pela Constituiçáo e pela lei”. Já no que concerne ao Pacto Internacional dos Direitos Civis e Políticos (PIDCP), um dos três instrumentos que integram a Carta Internacional dos Direitos do Homem, o seu artigo $14^{\circ}$ (Terceira parte) é claro na matéria de assistência judiciária gratuita, pois

\footnotetext{
9 V.g. Denise Cristina Mantovani Cera, in "Quais são os direitos de primeira, segunda, terceira e quarta geraçáo?”. Publicado por Rede de Ensino Luiz Flávio Gomes. Novelino, Marcelo. Direito Constitucional. 2009, 362/364.

10 V.g. Relatório Nacional de Direitos Humanos de Cabo Verde, elabora em 2010, pela Comissão Nacional para os Direitos Humanos e Cidadania, com a Cooperação do PNUD, p. 52.
} 
começa por sustentar que:

São iguais perante os tribunais de justiça' para mais adiante na alínea d) do seu $n^{\circ} .3$, esclarecer que 'qualquer pessoa acusada de uma infração penal terá direito, em plena qualidade, pelo menos às seguintes garantias: d) a estar presente no processo e (...) a ser-lhe atribuído um defensor oficioso, a título gratuito, no caso de não ter meios para o remunerar.

Por seu lado, o no. 3 do artigo $7^{\circ}$ da Carta Africana dos Direitos Humanos e dos Povos, estabelece que "toda a pessoa tem direito a que sua causa seja apreciada. Esse direito compreende: 3. O direito de defesa, incluindo o de ser assistido por um defensor de sua livre escolha”. Ora, a CRCV absorveu desses instrumentos internacionais, a ideia do direito à assistência judiciária gratuita, até porque o artigo $12^{\circ}$ da nossa Lei Magna dispóe sobre a "receção dos tratados e acordos na ordem jurídica interna, estatuindo no seu no. 1 que "o direito internacional geral ou comum faz parte integrante a ordem jurídica cabo-verdiana". Acrescenta ainda o no. 2 do mesmo artigo que "os tratados e acordos internacionais validamente aprovados ou ratificados, vigoram na ordem jurídica caboverdiana após a sua publicação oficial e entrada em vigor na ordem jurídica internacional e enquanto vincularem o Estado de Cabo Verde."

A assistência judiciária é um reflexo do direito de acesso à justiça, como já se viu. A sua transposição para diplomas de natureza infraconstitucional onde é melhor regulada e desenvolvida, viabiliza melhor a sua aplicação pelas instituições judiciais, o que acaba por ser determinante, já que deixa de ser uma mera declaração de intenção para passar a ter concretização prática por intermédio dos órgãos judiciais e demais instituições parceiras da justiça. Por conseguinte não é de se estranhar que as várias vertentes ou componentes do "acesso à justiça”, designadamente, a "assistência judiciária”, o "apoio jurídico e judiciário" e a própria "informação jurídica", surjam de algum modo abordados nos instrumentos legislativos de maior visibilidade internacional sobre os direitos humanos.

Ao nível constitucional cabo-verdiano o acesso à justiça é concebido não só como um direito fundamental em espécie, mas como um verdadeiro princípio sistémico. A sua expressão jusfundamental mais geral pode ser encontrada no atual artigo $22^{\circ}$ da Constituição da Re- 
pública. $^{11}$

\title{
3. ASSISTÊNCIA JUDICIÁRIA NA CONSTITUIÇÃO DA REPÚBLICA DE CABO VERDE
}

$\mathrm{Na}$ Constituição da República Cabo-verdiana (CRCV) podemos localizar várias disposiçóes que tratam de forma direta ou indireta a matéria concernente à assistência judiciária e ao acesso à justiça. De realçar desde já a esse propósito o disposto no artigo $22^{\circ} \mathrm{da}$ CRCV, uma disposição nuclear sobre o "acesso à justiça”, inserida na Parte II do Texto Constitucional sobre “direitos e deveres fundamentais". Estabelece esse artigo no seu no. 1 que "a todos é garantido o direito de acesso à justiça e de obter, em prazo razoável e mediante processo equitativo, a tutela dos seus direitos ou interesses legalmente protegidos". Numa primeira apreciação deve-se sustentar que, sem descurar os outros números do mesmo artigo, esta disposição constitucional deve ser entendida em conjugação com seu o no. 4 já que em decorrência desse mesmo número “a justiça não pode ser denegada por insuficiência de meios económicos ou indevida dilaçáo da decisáo”. Por esse prisma se pode aferir que para o legislador constitucional a carência de meios económico-financeiros não pode nem deve constituir um empecilho à representação em juízo por parte daquele que pretende fazer valer um direito ou interesse legalmente protegido.

\begin{abstract}
A Constituição, quando refere que a justiça não pode ser denegada por insuficiência de meios económicos, impóe a adoção de um conceito amplo de apoio ou de assistência judiciária, compreendendo não apenas o pagamento de preparos e de custas como também os próprios encargos com patrocínio judiciário.
\end{abstract}

O no. 1 do artigo $20^{\circ}$ da Constituição portuguesa trata de forma similar a ideia que se encontra plasmada no artigo $22^{\circ}$ da Constituição cabo-verdiana. Com efeito, o direito ao patrocínio judiciário constitui elemento essencial da garantia constitucional de acesso ao

\footnotetext{
$\overline{11}$ De acordo com o Relatório Nacional de Direitos Humanos de Cabo Verde, já referido, “(...) o ordenamento jurídico infraconstitucional densifica as orientaçôes constitucionais, reproduzindo e aprofundando o quadro estabelecido pela lei fundamental seja o nível substantivo, seja o nível processual e institucional". Segundo o documento "há que se destacar neste quadro a aprovação recente de vários diplomas, designadamente o Estatuto da Ordem dos Advogados (Lei n.o 35/III/88, de 18 de junho), a regulamentação da lei de acesso à justiça (Lei no. 35/III/88, de 18 de junho), pelo Decreto Regulamentar no 10/2004, de 2 de novembro e pela Portaria ${ }^{\circ}$. 1/2005, de 10 de janeiro), na modalidade de dispensa total de pagamento do profissional do foro, bem como a aprovação de reformas na esfera civil, com a aprovação do novo Código de Processo Civil (aprovado pelo Decreto-Legislativo no. 7/2010, de 01 de Julho). p. 53.
} 
direito e aos tribunais e, frequentemente, a lei vai mesmo ao ponto de impor a constituição obrigatória de advogado como condiçấo para que os interessados possam pleitear. ${ }^{12}$ Tais observaçôes aqui feitas relativamente à Constituição portuguesa aplicam-se perfeitamente às disposiçôes da Constituição cabo-verdiana sobre a matéria, não fora esta pertença da família jusconstitucional de matriz lusófona. ${ }^{13}$ Subsequentemente, o no ${ }^{\circ} .3$ do artigo $22^{\circ} \mathrm{da}$ CRCV determina que "todos têm direito de defesa, bem como à informação jurídica, ao patrocínio judiciário e a fazer-se acompanhar por advogado perante qualquer autoridade, nos termos da lei". Neste caso remete-se para o legislador ordinário a faculdade de estabelecer as condiçóes para que se possa dar vazão a um verdadeiro e efetivo exercício do direito de defesa, bem assim, a um verdadeiro e efetivo exercício do direito ao patrocínio judiciário. Remata por fim o n ${ }^{\circ} .6$ desse mesmo dispositivo da CRCV que:

Para a defesa dos direitos, liberdades e garantias individuais, a lei estabelece procedimentos judiciais céleres e prioritários que assegurem a tutela efetiva em tempo útil contra ameaças ou violaçóes desses mesmos direitos, liberdades e garantias.

Esses dispositivos não são mais do que reflexos do princípio do Estado de Direito Democrático em que nos encontramos inseridos, sendo precisamente um dos seus pilares, o respeito pelos direitos, liberdades e garantias fundamentais, de acordo com o $\mathrm{n}^{\circ} .1$ do artigo $2^{\circ} \mathrm{da}$ CRCV. ${ }^{14}$

\section{TRATAMENTO INFRACONSTITUCIONAL DA ASSISTÊNCIA JUDICIÁRIA}

Tem sido notável e ascendente o percurso legislativo feito pelas autoridades nacionais competentes na matéria. Desde a Lei no $.35 / \mathrm{III} / 88$, de 18 de julho, passando pelas medidas mais recentes visando a aceleração dos pedidos de assistência judiciária formulados por vítimas da violência baseada no género (VBG) e, a correr termos nos tribunais, até as Portarias vindo a lume, reforçando consideravelmente o montante das verbas destinadas ao serviço de assistência judiciária a prestar pela Ordem dos Advogados de Cabo Verde

\footnotetext{
$\overline{12}$ A esse propósito, v.g. Jorge Miranda e Rui Medeiro, ob. cit., anotaçóes ao artigo 22. ${ }^{\circ}$ da Constituiçấo da República Portuguesa, pp.170 a 205.

13 A esse respeito v.g. Jorge Bacelar Gouveia In "A influência da Constituição Portuguesa de 1976 nos sistemas jusconstitucionais lusófonos", 1993.

14 Referindo-se ao "direito de acesso ao direito" e "direito de acesso aos tribunais" como direitos conexos com o "acesso ao direito e aos tribunais" (artigo 20 da Constituição portuguesa), sustentam Gomes Canotilho e Vital Moreira que "qualquer deles constitui elemento essencial da própria ideia de Estado de Direito, não podendo conceber-se uma tal ideia sem que os cidadãos tenham conhecimento dos seus direitos, a proteçấo jurídica de que careçam e o acesso aos tribunais quando precisem".
} 
(OACV), é voz corrente que tem sido feita uma boa caminhada nesse domínio. Denotase assim um esforço sistemático dos sucessivos Governos da República no sentido de procurar uma dignificaçấo cada vez mais acentuada dos serviços de assistência judiciária a prestar pela Ordem dos Advogados de Cabo Verde (anterior IPAJ - Instituto de Patrocínio e Assistência Judiciários, criado pelo Decreto-Lei no ${ }^{\circ}$ 35/78, de 24 de abril, mais tarde alterado pelo Decreto-Lei ${ }^{\circ}$. 2/82, de 23 de janeiro, diplomas que aprovam o respetivo estatuto) e com o concurso dos profissionais do foro (advogados ou solicitadores judiciais). ${ }^{15}$

Sob o ponto de vista infraconstitucional são vários os diplomas que debruçam sobre a problemática da assistência judiciária. Referimo-nos particularmente, além da Lei no ${ }^{\circ} 35$ /III/88, de 18 de julho, já identificada, aos seguintes instrumentos: o Decreto no ${ }^{\circ}$ 99/88, de 5 de dezembro; o Decreto Regulamentar no. 10/2004, de 2 de novembro; a Lei no. 91/ VI/2006, de 9 de janeiro (Estatuto da Ordem de Advogados de Cabo Verde - OACV); a Portaria ${ }^{\circ} .1 / 20015$, de 10 de janeiro; a Portaria $n^{\circ} .2 / 2018$, de 9 de fevereiro, a Portaria $n^{\circ}$. 16/2017, de 17 de abril, a Portaria ${ }^{\circ}$. 40/2017, de 6 de novembro; e o Decreto-Lei no. 8/2014, de 27 de janeiro (assistência judiciária na VBG).

A começar pela Lei no. 35/III/88, de 18 de julho, trata-se de um diploma estruturante em matéria de assistência judiciária aos carenciados.

Por seu lado, o Decreto no. 99/88, de 5 de dezembro, que se seguiu à Lei no. 35/III/88, de 18 de julho, impóe a necessidade de regulamentação deste último diploma, já que comporta no seu bojo um conjunto de seis disposiçôes sobre o processo de concessão do benefício da assistência judiciária. O processo concernente ao pedido da assistência judiciária é composto por um conjunto de cinco atos que poderão eventualmente, ocorrer, quando se formula um pedido de assistência judiciária e que comina com o recurso da decisão final caso a ele houver lugar. $\mathrm{O}$ processo começa por um pedido devidamente instruído com meios de prova sobre a insuficiência económica, a ser interposto pelo interessado junto do tribunal onde o processo vai correr seus termos. Segue-se a informação da secretaria sobre

15 O Instituto do Patrocínio e Assistência Judiciários (IPAJ) foi criado pelo Decreto-Lei n. ${ }^{\circ}$ 35/78, de 24 de abril, de 1978, mais tarde alterado pelo Decreto-Lei n. ${ }^{\circ}$ 2/82, de 23 de janeiro, diploma esse que aprovou os respetivos Estatutos. O IPAJ foi extinto pelo Decreto-Lei n.o 51/2000, de 4 de dezembro, o mesmo diploma que criou a Ordem dos Advogados de Cabo Verde (OACV), a 4 de dezembro de 2000. O diploma que criou a OACV instituiu uma Comissão Instaladora composta por seis membros, designados pela Ministra da Justiça - ouvidos os advogados - para, no prazo de cento e vinte dias, realizar as primeiras eleiçóes para os órgãos da $\mathrm{OACV}$, como resulta do despacho da Ministra da Justiça de 12 de janeiro de 2001, publicado no BO I série, n. ${ }^{3}$, de 29 de janeiro. As primeiras eleiçóes tiveram lugar no dia 30 de abril de 2001, com uma lista única encabeçada pela Dra. Lígia Arcângela Lubrino Dias Fonseca, que foi eleita a primeira Bastonária e, tomou posse no dia 19 de maio de 2001. In: www.caboverde,oa.pt. 
a capacidade económica do requerente. Depois o processo é remetido ao juiz para decisão. Do despacho do juiz pode o requerente reclamar ou interpor recurso, consoante os casos.

O Decreto Regulamentar no. 10/2004, de 2 de novembro, é também um diploma que pretende melhorar o serviço de prestação da assistência judiciária ao litigante carente de recursos para poder estar em juízo, assegurando que a sua causa seja patrocinada por profissional do foro, qualificado. $\mathrm{O}$ erário público passou a disponibilizar os meios financeiros necessários à garantia de uma maior dignidade ao instituto de assistência judiciária. A Ordem dos Advogados por seu turno passou a estar mais habilitada a assegurar uma assistência judiciária mais qualificada aos carenciados.

Com a Portaria $n^{\circ} .1 / 2005$, de 10 de janeiro, fica aprovada a tabela de honorários de assistência judiciária. Há um esforço do legislador no sentido de remunerar melhor a compensação pela prestação dos serviços de assistência judiciária.

No que concerne ao Estatuto da Ordem dos Advogados (OACV) dispóe o seu artigo 14º, sob o título de "dever de colaboração" que:

Todas as entidades públicas, autoridades judiciárias e policiais e órgáos de polícia criminal e todas as pessoas singulares ou coletivas privadas têm o dever de colaborar com os órgáos da OACV no exercício das suas atribuiçóes, sem prejuízo dos deveres de sigilo profissional ou do segredo de justiça.

$\mathrm{O}$ artigo $120^{\circ}$ do mesmo Estatuto, sob o título “deveres dos advogados para com a comunidade" estabelece na sua alínea c) que o advogado deve "colaborar no acesso ao direito, designadamente participando no serviço público de assistência judiciária, defesa oficiosa, consulta e informação jurídicas, nos termos da lei e dos regulamentos da OACV”. Em conformidade com o disposto no artigo $137^{\circ}$ do Estatuto da OACV, inscreve-se entre os deveres gerais do advogado para com o cliente, os seguintes:

a) estudar e tratar com cuidado e zelo as questóes que lhe forem confiadas, assumindo a firme defesa dos interesses que representa ou assiste e, utilizando para o efeito, todos os recursos da sua experiência e conhecimentos dentro dos limites estabelecidos pela lei e pela ética profissional b) dar ao cliente com lealdade e franqueza a sua opiniáo fundamentada sobre o merecimento do direito ou pretensão que o mesmo invoca; e) guardar segredo profissional; f) comparecer pontualmente a todas as diligências, atos e termos do processo em que seja obrigatória, necessária ou conveniente a sua presença; l) não abandonar o patrocínio, sem motivo justificado e sem ter sido legal- 
mente substituído.

O advogado possui, de acordo com o artigo $169^{\circ}$ do Estatuto da OACV, o:

Direito de comunicar, pessoal e reservadamente, com os seus patrocinados, seja qual for a situação em que estes se encontrem, nomeadamente quando presos ou detidos, em estabelecimento civil ou militar.

De acordo com as alíneas do artigo $46^{\circ}$ do Estatuto da OACV compete ao seu Conselho Coordenador "regulamentar e coordenar internamente, no âmbito nacional, os serviços públicos de assistência judiciária, de consulta e de informação jurídicas”.

Todo o anteriormente exposto é reflexo do estabelecido no artigo $22^{\circ}$ da Constituição da República, que estatui sobre “os advogados”, representando este, o capítulo V do título V do texto da Lei Constitucional, intitulado "do poder judicial". Segundo o no. 1 desse artigo "o advogado no exercício da sua funçáo é um servidor da justiça e do direito e um colaborador indispensável na administraçáo da justiça”. É imposição constitucional, o direito que o advogado tem "de comunicar pessoal e reservadamente com o seu patrocinado, mesmo quando este se encontre preso ou detido", segundo o seu $n^{\circ}$. 4. Por fim determina o $n^{\circ} .5$ da mesma disposição que "o exercício da função de advogado sujeita-se a regras deontológicas, implica responsabilidade profissional e submete-se à regulação e disciplina da Ordem dos Advogados de Cabo Verde, nos termos da lei. As disposiçóes do estatuto da OACV traduzem boa parte daquilo a que alude esse artigo $22^{\circ}$ da Constituição.

A Portaria no. 2/2018, de 9 de fevereiro, encarregou-se de aprovar uma nova tabela de honorários a serem prestados como contrapartida dos serviços de assistência judiciária, para cada tipo de processo em causa. Melhora-se consideravelmente a dignificação do serviço de prestação da assistência judiciária, com esta Portaria. Este diploma revoga a anterior Portaria $n^{\circ}$. 1/2005, de 10 de janeiro que, estabelecia também sobre o mesmo assunto, mas, com menor projeção financeira sobre os serviços de assistência judiciária prestados pelos profissionais do foro.

Recentemente, mais concretamente, em março de 2018, saiu, ao abrigo do disposto $\mathrm{n}^{\mathrm{o}}$. 6 do artigo $8^{\circ}$ do Decreto Regulamentar no. 10/2004, de 8 de novembro, a Portaria $n^{\circ}$. 8/2018, de 19 de março, que suspende a vigência da anterior Portaria no. 2/2018, de 9 de fevereiro, que aprovou a nova tabela dos honorários da assistência judiciária, 
cuidando assim, da criaçáo de uma nova modalidade de pagamento aos advogados e advogados estagiários. Esta nova Portaria procede de igual modo à repristinação dos efeitos da Portaria no ${ }^{\circ}$ 1/2005 de 10 de janeiro de 2005, retroagindo os seus efeitos a 1 de janeiro de 2018. Com essa medida, o Ministério da Justiça e Trabalho concebe uma plataforma informática de gestão da assistência judiciária, com a finalidade de todas as instituiçôes envolvidas no processo, estarem devidamente alinhadas no propósito de garantir um sistema cada vez mais eficaz de prestação da assistência judiciária. Por outro lado, isso traduz a grande preocupaçáo do Governo no reforço da assistência judiciária, preocupação essa que consta do seu Programa aprovado pela Assembleia Nacional em 2016, propondo reformar o sistema de assistência judiciária, de modo a assegurar com oportunidade, efetividade e qualidade, o patrocínio judiciário gratuito aos que não têm recursos para arcar com os custos correspondentes.

No que respeita à violência basada no género, VBG, regulado pelo Decreto-Lei $\mathrm{n}^{\mathrm{o}}$. 8/2014, de 27 de janeiro, existe um dispositivo que se ocupa especificamente da assistência judiciária a ser prestada às vítimas deste tipo específico de criminalidade. Por outro lado, em virtude da particularidade com que se reveste esta tipologia de crime e de todas as suas implicações a nível familiar e social do agressor e da vítima, optouse recentemente por medidas no sentido de imprimir maior celeridade a tais tipos de processos, designadamente, concedendo prioridade aos processos da VBG e fixando em 180 dias, o prazo máximo para a conclusão de processos de VBG que eventualmente tenham dado entrada nos tribunais. O diploma em questáo contém um dispositivo especial em matéria de pedido de assistência judiciária formulado pela vítima da VBG. Essa disposição especial destina-se a dar uma atenção particular à vítima da violência doméstica baseada no género (VBG) em matéria de assistência judiciária. De acordo com o estabelecido no $n^{\circ} .1$ do seu artigo $22^{\circ}$ :

\footnotetext{
Enquanto não for decidido o pedido de assistência judiciária apresentado pela vítima nos termos da Lei n. ${ }^{\circ}$ 35/III/88, de 18 de julho, esta pode intervir em qualquer ato processual cível, nos termos legais, ou constituir-se assistente em processos-crime, sem necessidade de pagamento de taxas, emolumentos ou encargos de qualquer natureza.
}

Como é bem de ver, os efeitos e as consequências da VBG não se compadecem, neste particular, com demoras próprias da burocracia judicial. Acrescenta o seu $\mathrm{n}^{\circ} .2$ que "no caso de indeferimento do pedido de assistência judiciária, a vítima deve pagar pelos atos já realizados nos processos cíveis ou crime, mas não pelo próprio pedido de assistência judiciária”. Por essa disposição se pode aferir que o legislador propôs-se proteger o instituto 
da assistência judiciária, em si, dispensado a vítima da VBG do seu pagamento, em caso de indeferimento do seu pedido nesse sentido. Por fim, remata o $n^{\circ} .3$, da seguinte forma: "os pedidos de assistência judiciária em processos de natureza criminal ou cível devem ser decididos em caráter de urgência”. Mais uma vez, neste dispositivo traz-se à tona a natureza prioritária do pedido de assistência judiciária formulado pela vítima da VBG. Os demais pedidos que eventualmente hajam sido formulados junto da secretaria judicial, terão que aguardar pela decisão, nunca antes de se decidir em primeiro lugar e, com carater de urgência, aquele, formulado pela vítima da VBG. O Decreto-Lei $\mathrm{n}^{\circ}$. 8/2014, de 27 de janeiro regula de forma especial a assistência judiciária nos crimes da VBG (violência baseada no género). Dada a particularidade de que se reveste esta tipologia de crime e todas as suas implicaçóes a nível familiar e social do agressor e da vítima, optou-se recentemente por medidas no sentido de imprimir maior celeridade a tais tipos de processos, designadamente, concedendo prioridade aos processos da VBG e fixando em 180 dias, o prazo máximo para a conclusão de processos de VBG que eventualmente tenham dado entrada nos tribunais. Por fim, no que respeita à Portaria no ${ }^{\circ} .40 / 2017$, de 6 de novembro, este diploma, ao mesmo tempo que acresce à quantia de 17.500.000\$00 inicialmente fixados pela Portaria $\mathrm{n}^{\circ}$. 16/2017, de 17 de abril, o valor de 19.000.000\$00, fixa o valor da assistência judiciária para o ano de 2017, em 36.500.000\$00.

\section{INSTITUIÇÓES INTERVENIENTES NA PROMOÇÁO DA ASSISTÊNCIA JUDICIÁRIA E A IMPLEMENTAÇĀO FORMAL E MATERIAL DO INSTITU- TO DA ASSISTÊNCIA JUDICIÁRIA}

$\mathrm{Na}$ promoção e salvaguarda da assistência judiciária aos carenciados, em Cabo Verde, temos a destacar as seguintes instituições: a Ordem dos Advogados de Cabo Verde (OACV) e os Tribunais, de um lado e, as Câmaras Municipais do outro. A Ordem dos Advogados traduz-se num órgão constitucionalmente incumbido dessa função cabendo ao advogado um papel de primeiro plano enquanto "servidor da justiça e do Direito e um colaborador indispensável da administraçáo da Justiça”. É o que resulta do disposto no artigo $229^{\circ}$ da Constituição. Em Estatuto próprio, como já se viu, esta ordem profissional admite e regula essa função. No que respeita aos tribunais, compete aos juízes dos processos nomearem as defesas oficiosas e em concertação com a Ordem dos Advogados colaborarem na designaçáo do profissional encarregado de assegurar a assistência judiciária aos carenciados, lá onde se mostrar essa necessidade ou entâo, indicando-a de entre uma lista de advogados à sua disposição incumbindo um deles para desempenhar essa função em juízo. Neste particular os órgãos jurisdicionais estarão 
viabilizando aos cidadáos aquilo que Gomes Canotilho chama de "direitos ao acesso e utilização de prestaçóes estaduais." ${ }^{16}$

No que respeita à implementação formal e material do instituto da assistência judiciária, importa salientar que a legislação cabo-verdiana estabelece que o Estado deve disponibilizar à Ordem dos Advogados $(\mathrm{OACV})$ recursos financeiros necessários à prestação da assistência judiciária aos cidadãos que por insuficiência de meios económicofinanceiros, se vêm privados de um acesso efetivo à justiça. É assim que o Estado vem inscrevendo no seu orçamento anual uma verba destinada a dar guarida a esse imperativo constitucional, razão porque, anualmente, através do Ministério da Justiça e Trabalho se disponibiliza um determinado montante à $\mathrm{OACV}$ destinado a assegurar esse serviço em favor dos desvalidos da sorte. Trata-se de uma medida com assento constitucional já que, de acordo com o disposto no no 1 do artigo $229^{\circ}$ da CRCV “o advogado, no exercício da sua função é um servidor da justiça e do direito e um colaborador indispensável da administraçâo da justiça”. O legislador constitucional deixou assim para os meandros da legislaçâo ordinária, estabelecer quando, em que medida e em que circunstâncias o advogado, através da sua organização sócio profissional, prestará esse apoio e essa colaboração na administração da justiça no Estado de Cabo Verde. Pode-se dizer, por conseguinte, que a assistência judiciária aos carenciados está garantida e salvaguardada no sistema jurídico cabo-verdiano, não apenas sob o ponto de vista formal, mas também, na perspetiva material da sua efetiva implementação e salvaguarda, na prática. Tem-se levantado a questáo do montante disponibilizado para a garantia efetiva da assistência judiciária aos carenciados, mas trata-se de uma questão que será sempre colocada de forma sistemática e permanente na medida em que a Justiça, quanto mais eficaz e eficiente for, mais demandas irá implicar, pois, dessa forma os cidadãos se sentirão mais seguros e mais atraídos para demandá-la, cada vez mais e em maior número. Assim, os recursos disponibilizados num país como Cabo Verde terão que obedecer necessariamente a uma gestáo ordenada e criteriosa. Outro problema prende-se com a definição e o controlo daqueles que efetivamente buscam a justiça numa efetiva situação de fragilidade ou debilidade económico-financeira. A ideia com que se fica é que por vezes, cidadãos que poderiam perfeitamente suportar os custos com a justiça, afinal, aparecem exibindo um atestado de pobreza e como tal, configurados como sendo economicamente fragilizados,

$\overline{16}$ De acordo com o constitucionalista "os poderes públicos têm uma significativa quota de responsabilidade no desempenho de tarefas económicas, sociais e culturais, incumbindo-lhes pôr à disposiçáo dos cidadãos prestaçôes de vária espécie, como instituiçôes de ensino, saúde, segurança, transportes, telecomunicaçóes, etc." Mais adiante, sustenta o mesmo autor que "consequentemente, eles beneficiam da natureza de direitos judiciáveis, permitindo aos seus titulares o recurso aos tribunais a fim de reclamar a manutenção do nível de realização que os direitos fundamentais tenham adquirido". José Joaquim Gomes Canotilho, In Direito Constitucional, 1986, p. 449-450. 
quando afinal não o são.

\section{CONSIDERAÇÓES FINAIS}

A consagração na Lei Fundamental de 1992 da figura da assistência judiciária subsequentemente absorvida e desenvolvida em legislaçóes de menor valia hierárquica, por um lado, a par da criação de condições institucionais para a sua efetiva implementação prática, por outro, tudo isso junto, traduz verdadeiramente uma real e efetiva sinceridade do legislador constitucional nessa matéria. Nesse sentido apesar de existir alguma discordância em torno da maior ou menor quantidade dos recursos financeiros disponibilizados para a melhor garantia e salvaguarda do serviço de assistência judiciária a prestar pela Ordem dos Advogados, aos cidadãos carenciados, pode-se dizer que a prestação desse serviço em Cabo Verde encontra-se assente em bases sólidas e, os resultados práticos estão à vista de quem os quiser enxergar. Não obstante é sempre desejável que mais recursos sejam disponibilizados para que a eficácia da prestação desses serviços se eleve de nível. Mas num país como o nosso dotado de escassos recursos económico-financeiros e materiais não se pode negar a razoabilidade do patamar já alcançado nesse domínio. Ademais a experiência que o nosso país acumula nesse domínio é de mais de trinta anos o que proporciona às entidades cabo-verdianas uma certa à-vontade e tranquilidade em lidar com essa problemática. Afora isso existem pormenores a serem melhor trabalhados sobretudo no domínio da operacionalização prática da medida. Referimo-nos particularmente a situaçôes em que a capacidade financeira do assistido não é devidamente ponderado, a ponto de indivíduos que bem poderiam suportar as custas do processo acabam por furar a malha do controle das possibilidades económicas de quem procura a justiça e apresentam-se como alguém presumivelmente desprovido de recursos.

Outra questão que tem vindo a ser aventada prende-se com situaçóes em que o assistido, no início do processo, se apresenta como carenciado, mas que, a meio do processo ou no termo do mesmo deixa de sê-lo em decorrência de indemnizaçóes acordadas com a contraparte em juízo ou em virtude de sentenças condenatórias que possam arbitrar indemnizaçóes ou compensaçóes de monta, a favor daquele que ab intio apresentou-se como carenciado. Tem se questionado se nesses casos, não será de justiça impor sobre aquele que deixou de ser carenciado a obrigação de comparticipar nas despesas com o processo ou mesmo o pagamento integral dos encargos com o pleito (advogado, custas e imposto de justiça, entre outros). 
Por todo o exposto se pode concluir que se encontra minimamente salvaguardada essa tarefa do Estado no ordenamento jurídico cabo-verdiano, no sentido de garantir a todos as condiçóes mínimas de acesso à justiça, acautelando nessa matéria a prestação desses serviços aos mais desvalidos da sorte. Para o futuro fica a sugestâo de que se deve ir limando as arestas lá onde se fizer sentir essa necessidade e ainda, tão logo, sejam criadas condiçôes as mais desejáveis, que sejam libertados mais recursos para que o nível da prestação dos serviços de assistência judiciária aos mais carentes, se eleve, consolidando deste modo o grau de satisfação dos cidadãos e libertando o Estado das pressóes que legitimamente são exercidas por aqueles que de algum modo ainda não sentiram os benefícios da prestação desses serviços.

\section{REFERÊNCIAS}

FONTES DOUTRINÁRIAS

CABRITO, B. G.; HENRIQUES, V. Introduçáo à Política. Tomo 1, 6.ed. Lisboa: Texto Editora Lda., 1990.

CANOTILHO, J. J. G. E MOREIRA, V. Constituiçáo da República Portuguesa Anotada. 2.ed. revista e ampliada, v. 1, Coimbra Editora, 1984.

CANOTILHO, J. J. G. Direito Constitucional. 4.ed. Coimbra: Livraria Almedina, 1986.

GOUVEIA, J. B. A Influência da Constituiçáo Portuguesa de 1976 nos sistemas jusconstitucionais lusófonos. Lisboa, 1993.

MIRANDA, J.; MEDEIROS, R. Constituiçáo Portuguesa Anotada. Tomo I, Introdução Geral, Preâmbulo, artigos $1^{\circ}$ a 79º. Coimbra: Editora Limitada, 2005.

NEVES, P. A. Textos de Introduçáo à Política. Porto: Porto Editora, Lda., v. 1, 1983.

PRATA, A. Dicionário Jurídico. 4.ed., Direito Civil, Direito Processual Civil e Organizaçáo Judiciária, com a colaboração de Jorge Carvalho. Coimbra: Edições Almedina SA, 2006.

SILVA, J. A. da. Aplicabilidade das normas constitucionais. Revista dos Tribunais. São 
Paulo, 1968.

\section{FONTES JURÍDICAS}

Constituição cabo-verdiana de 1980, publicada no suplemento ao Boletim Oficial n. ${ }^{\circ} 41$, de 13 de outubro, de 1980.

Constituição da República de Cabo Verde, de 1992.

Declaração Universal dos Direitos Humanos, aprovada pela Assembleia Geral da ONU a 10 de dezembro de 1948.

Carta Africana dos Direitos do Homem e dos Povos, adotada na $115 .{ }^{\text {a }}$ Conferência dos Chefes de Estado e do Governo, na sua XVI Sessão Ordinária realizada em Monróvia (Libéria) de 17 a 20 de julho de 1979.

Lei no. 35 /III/88, de 18 de julho.

Decreto no. 99/88, de 05 de dezembro.

Decreto Regulamentar no. 10/2004, de 02 de novembro.

Lei no. 91/VI/2006, de 09 de janeiro.

Decreto-Lei no ${ }^{\circ}$ 8/2014, de 27 de janeiro.

Portaria n. ${ }^{\mathrm{o}} 1 / 20015$, de 10 de janeiro.

Portaria n. ${ }^{\circ}$ 16/2017, de 17 de abril.

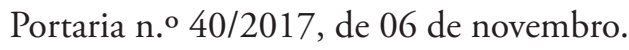

Portaria n. ${ }^{\circ}$ 2/2018, de 09 de fevereiro. 